\title{
Influence of Parameters on Tribological Behaviour of E-Glass Fiber Reinforced Epoxy Composites
}

\author{
N. Ozsoy*, M. Ozsoy and A. Mimaroglu \\ Sakarya University, Mechanical Engineering Department, Sakarya, Turkey
}

\begin{abstract}
E-glass fiber reinforced epoxy composites were fabricated by hand lay up method and tested for investigating tribological behaviours. Wear behaviours of composites $0^{\circ}, 90^{\circ}$ and $\left[0^{\circ} / 90^{\circ}\right]$ oriented were investigated by pin on disc wear tester device for a constant distance $(1000 \mathrm{~m})$ and the design of experiments approach using the Taguchi method was employed. The tests were conducted sliding against a steel disc (60 HRC) under different sliding and loading conditions. Signal to noise ratio and analysis of variance (ANOVA) were used to investigate the influence of parameters on the wear rate and coefficient of friction.
\end{abstract}

DOI: 10.12693/APhysPolA.128.B-55

PACS: 81.05.Qk, 07.05.Fb, 62.20.Qp

\section{Introduction}

Glass-fibre-reinforced polymer with thermoset resin is an attractive material that is economically desired. Its application at low temperatures and under service terms is easy, when this material is compared to advanced polymer composites with complex molecule structure, high strength and working under terms of difficult service [1]. So many researchers conducted works about glass fiber reinforced composites.

Yousif and El-Tayeb studied three-body abrasive wear of chopped strand mat glass fibres reinforced polyester (CGRP) for three principal orientations of the fibres, i.e. parallel orientation ( $\mathrm{P}-\mathrm{O})$, antiparallel orientation $(\mathrm{AP}-\mathrm{O})$ and normal orientation $(\mathrm{N}-\mathrm{O})[2]$. Larsen et al. worked about comparison of friction and wear for an epoxy resin reinforced by a glass or a carbon/aramid hybrid weave [3]. Suresha et al. investigated threebody abrasive wear behaviour of carbon-epoxy (C-E) and glass-epoxy (G-E) composites. They found that the wear volume loss increased with increasing load/abrading distance [4]. Basavarajappa and Ellangovan studied the dry sliding wear characteristics of a $\mathrm{G}-\mathrm{E}$ composite, filled with both silicon carbide ( $\mathrm{SiCp}$ ) and graphite ( $\mathrm{Gr}$ ) using a pin-on-disc test apparatus. They found that the influence of applied load is greater on specific wear rate [5].

Experimental working for tribological properties needs to spend too much time so it is hard. The Taguchi method is able to avoid this. Many researchers used this method [6-10]. Design of experiment (DOE) is one of the important and powerful statistical techniques to study the effect of multiple variables simultaneously and involves a series of steps which must follow a certain sequence for the experiment to yield an improved understanding of process performance [5]. Taguchi is one of the technique which reduces the experiment numbers and helps to predict results. The plan of experiments is

*corresponding author; e-mail: nerken@sakarya.edu.tr generated in the Taguchi method by the use of standard orthogonal arrays. The experimental results are then analyzed by using analysis of mean and analysis of variance (ANOVA) of the influencing factors [11].

In the present work it is purposed to investigate tribological properties of E-glass fiber reinforced epoxy composites. Also it is aimed to plan wear experiments by the Taguchi method and analyse results with ANOVA.

\section{Experimental work}

In this study the materials used for composite preparing were unidirectional E-glass fiber as reinforcement and epoxy as matrix material.

Composites were manufactured by hand lay up process. Fabric was cut into squares $20 \times 20 \mathrm{~cm}^{2}$. Epoxy resin (MGS L285) was mixed with hardener (HGS L285) in mass ratio of $100 / 40$ as recommended by supplier. Firstly wax was applied to the surface in order to separate composite easily from the surface after curing. $0^{\circ}$ or $90^{\circ}$ orientation of fiber laid out and epoxy was poured over each layer. Layers were compressed with a roll to free air bubbles. This process was repeated until producing required thickness. Composites were cured at room temperature for $24 \mathrm{~h}$. After that $6 \times 6 \times 3 \mathrm{~mm}^{3}$ specimens were cut from cured composite sheet and then they were glued to metal pins.

A pin on disc wear testing machine was used to investigate the dry sliding wear characteristics of composites according to ASTM G99-95 [12] standards. The initial weight of the specimen was measured using an electronic balance machine with accuracy of $0.0001 \mathrm{~g}$. During the test the pin was pressed against the counter part rotating against EN19 steel disc with hardness of $60 \mathrm{HRC}$ by applying the load. After running through a fixed sliding distance of $1000 \mathrm{~m}$, the specimens were removed, cleaned with acetone, dried and weighted to determine the weight loss due to wear. The difference in the weight measured before and after test gave the sliding wear of the composite specimen. The density of the specimens were measured and then the sliding wear of the composite was calculated according to Eq. (1) where $\Delta m$ is difference in mass, $\rho$ is density and $d$ is the sliding distance 


$$
\text { Wear rate }=\frac{\Delta m}{\rho d} .
$$

Dry sliding wear tests were performed with three parameters: applied load, sliding speed and orientation of fiber layers. According to the rule that degree of freedom for an orthogonal array should be greater than or equal to sum of those wear parameters, an $\mathrm{L}_{9}$ orthogonal array which has 9 rows and 3 columns was selected.

TABLE I

Process parameters with their values at three levels.

\begin{tabular}{c|c|c|c}
\hline \hline level & load $[\mathrm{N}]$ & $\begin{array}{c}\text { sliding speed } \\
{[\mathrm{m} / \mathrm{s}]}\end{array}$ & $\begin{array}{c}\text { orientation of } \\
\text { fiber layers }\end{array}$ \\
\hline 1 & 20 & 0.6 & $0^{\circ}$ \\
2 & 30 & 0.8 & $90^{\circ}$ \\
3 & 40 & 1 & $0^{\circ} / 90^{\circ}$
\end{tabular}

The process variables are given in Table I. The response variables to be studied were wear rate and coefficient of friction.

The experiments were conducted based on the run order generated by the Taguchi model and the results were obtained. The analysis of the experimental data were carried out using MINITAB 15 software, which is specially used for DOE applications. The experimental results were transformed into signal-to-noise $(\mathrm{S} / \mathrm{N})$ ratios. $\mathrm{S} / \mathrm{N}$ ratio is defined as the ratio of the mean of the signal to the standard deviation of the noise. The $\mathrm{S} / \mathrm{N}$ ratio indicates the degree of the predictable performance of a product or process in the presence of noise factors [13]. Process parameter settings with the highest $\mathrm{S} / \mathrm{N}$ ratio always yield the optimum quality with minimum variance [14]. The $\mathrm{S} / \mathrm{N}$ ratio for wear rate and coefficient of friction using "smaller the better" characteristic, which can be calculated as logarithmic transformation of the loss function, is given as

$$
\mathrm{S} / \mathrm{N}=-10 \log \left(\frac{1}{n\left(\sum y^{2}\right)}\right),
$$

where $y$ is the observed data (wear rate or coefficient of friction) and $n$ is the number of observations.

\section{Results and discussions}

It can be observed from Table II that optimum condition for wear rate is 1st experiment and for the coefficient of friction - 3rd experiment.

Results of $\mathrm{L}_{9}$ orthogonal array for E-glass fiber reinforced epoxy composites.

\section{TABLE II}

\begin{tabular}{c|c|c|c|c|c|c|c}
\hline \hline $\begin{array}{c}\text { exp. } \\
\text { no. }\end{array}$ & $\begin{array}{c}\text { load } \\
{[\mathrm{N}]}\end{array}$ & $\begin{array}{c}\text { sliding } \\
\text { speed } \\
{[\mathrm{m} / \mathrm{s}]}\end{array}$ & $\begin{array}{c}\text { orientation } \\
\text { of fiber } \\
\text { layers }\end{array}$ & $\begin{array}{c}\text { wear rate } \\
{\left[\mathrm{mm}^{3} / \mathrm{m}\right]}\end{array}$ & $\begin{array}{c}\text { coefficient } \\
\text { of friction }\end{array}$ & $\begin{array}{c}\text { S/N ratio } \\
\text { of wear } \\
\text { rate }[\mathrm{dB}]\end{array}$ & $\begin{array}{c}\text { S/N ratio of } \\
\text { coefficient of } \\
\text { friction }[\mathrm{dB}]\end{array}$ \\
\hline 1 & 20 & 0.6 & 0 & 0.0002797 & 0.682379 & 71.0655 & 3.31949 \\
2 & 20 & 0.8 & 90 & 0.0003497 & 0.688429 & 69.1273 & 3.24281 \\
3 & 20 & 1 & $0 / 90$ & 0.0005634 & 0.635816 & 64.9840 & 3.93338 \\
4 & 30 & 0.6 & 90 & 0.0009091 & 0.748294 & 60.8279 & 2.51855 \\
5 & 30 & 0.8 & $0 / 90$ & 0.0014085 & 0.774008 & 57.0252 & 2.22509 \\
6 & 30 & 1 & 0 & 0.0017483 & 0.690543 & 55.1479 & 3.21618 \\
7 & 40 & 0.6 & $0 / 90$ & 0.0024648 & 0.705750 & 52.1644 & 3.02699 \\
8 & 40 & 0.8 & 0 & 0.0018182 & 0.745702 & 54.8073 & 2.54869 \\
9 & 40 & 1 & 90 & 0.0016783 & 0.670350 & 55.5025 & 3.47396
\end{tabular}

The control parameter with the strongest influence was determined by the difference between the maximum and minimum value of the mean of $\mathrm{S} / \mathrm{N}$ ratios. Higher the difference between the mean of $\mathrm{S} / \mathrm{N}$ ratios, the more influential was the control parameter. From Table III it can be observed that load is the dominant parameter on the wear rate. Orientation of fiber is the second parameter that influences the wear rate followed by sliding speed. From Table IV it can be observed that sliding speed is the dominant parameter on the coefficient of friction followed by load and orientation of fibers.

\subsection{Analysis of variance and the effects of parameters}

ANOVA is used to analyse the influence of wear parameters like sliding speed, applied load and orientation of fibers on the tribological performance characteristics: wear and coefficient of friction. This analysis was carried out for the level of significance of $5 \%$ with $95 \%$ confidential level. Table $\mathrm{V}$ shows the results of ANOVA analysis for wear rate and coefficient of friction. The total sum of squares value is used to measure the relative influence of the factors. The larger value of sum of squares, the more influential the factor is for controlling the responses. These values are used to determine the percentage contribution factors. From Table V it is found that load $(82.60 \%)$ is the most significant factor on wear rate, second factor is orientation of fiber $(8.69 \%)$ and third factor is sliding speed (2.19\%).

On the other hand, according to the analysis of variance for coefficient of friction, sliding speed $(50.45 \%)$ is the most significant factor followed by load. The influence of orientation of fibers factor is very low. 
TABLE III

Response table for $\mathrm{S} / \mathrm{N}$ ratio for wear rate - smaller is better.

\begin{tabular}{c|c|c|c}
\hline \hline level & load & sliding speed & orientation \\
\hline 1 & 68.39 & 61.35 & 60.34 \\
2 & 57.67 & 60.32 & 61.82 \\
3 & 54.16 & 58.54 & 58.06 \\
$\Delta$ & 14.23 & 2.81 & 3.76 \\
rank & 1 & 3 & 2
\end{tabular}

TABLE IV

Response table for $\mathrm{S} / \mathrm{N}$ ratio for coefficient of friction - smaller is better.

\begin{tabular}{c|c|c|c}
\hline \hline level & load & sliding speed & orientation \\
\hline 1 & 3.499 & 2.955 & 3.028 \\
2 & 2.653 & 2.672 & 3.078 \\
3 & 3.017 & 3.541 & 3.062 \\
$\Delta$ & 0.845 & 0.869 & 0.050 \\
rank & 2 & 1 & 3
\end{tabular}

TABLE V

ANOVA results.

\begin{tabular}{c|c|c|c|c|c|c|c}
\hline \hline factors & DOF & seq. SS & adj. SS & adj. MS & F-test & P-value & \% contribution \\
\hline \multicolumn{7}{c}{ wear rate } \\
\hline $\begin{array}{c}\text { load } \\
\text { sliding }\end{array}$ & 2 & 0.0000038 & 0.0000038 & 0.0000019 & 11.32 & 0.081 & 82.60 \\
speed & 2 & 0.0000000 & 0.0000000 & 0.0000000 & 0.10 & 0.913 & 2.19 \\
orientation & 2 & 0.0000004 & 0.0000004 & 0.0000002 & 1.12 & 0.472 & 8.69 \\
error & 2 & 0.0000003 & 0.0000003 & 0.0000002 & & & 6.52 \\
total & 8 & 0.0000046 & & & & 100 \\
\hline \multicolumn{7}{c}{ coefficient of friction } \\
\hline $\begin{array}{c}\text { load } \\
\text { sliding }\end{array}$ & 2 & 0.0071203 & 0.0071203 & 0.0035602 & 16.83 & 0.056 & 46.61 \\
speed & 2 & 0.0077073 & 0.0077073 & 0.0038537 & 18.22 & 0.052 & 50.45 \\
orientation & 2 & 0.0000239 & 0.0000239 & 0.0000119 & 0.06 & 0.947 & 0.15 \\
error & 2 & 0.0004231 & 0.0004231 & 0.0002115 & & & 2.76 \\
total & 8 & 0.0152746 & & & & \\
\hline
\end{tabular}

DOF - degree of freedom; Seq SS - sequential sum of squares;

Adj SS - adjusted sum of squares; Adj MS — adjusted mean squares.

\subsection{Confirmation of Taguchi prediction}

According to the Taguchi analyses in MINITAB 15 the response factors can be predicted. Table VI shows the comparison of the predicted wear rate and frictional force with the actual response under study for load: $20 \mathrm{~N}$, sliding velocity: $0.6 \mathrm{~m} / \mathrm{s}$, orientation $=0$. The error is calculated as the difference between actual and predicted values of $\mathrm{S} / \mathrm{N}$ ratio.

\section{Conclusions}

Dry sliding wear and coefficient of friction of the composite material under different loads and sliding velocities were successfully analysed using the Taguchi design of experiment.

Applied load (82.60\%) had the highest influence on the wear rate of E-glass fiber reinforced epoxy composites. According to the analysis of variance for coefficient of friction, sliding speed $(50.45 \%)$ is the most significant factor.
TABLE VI

Verification of Taguchi prediction.

\begin{tabular}{|c|c|c|c|}
\hline Actual value & Predicted value & Actual value & Predicted value \\
\hline \multicolumn{2}{|c|}{ Wear rate } & \multicolumn{2}{|c|}{ Coefficient of friction } \\
\hline 0.0002797 & 0.0004042 & 0.682379 & 0.678052 \\
\hline \multicolumn{4}{|c|}{$\mathrm{S} / \mathrm{N}$ ratio } \\
\hline 71.0655 & 69.9402 & 3.31949 & 3.36944 \\
\hline \multicolumn{4}{|c|}{ Predicted error of $\mathrm{S} / \mathrm{N}$ ratio $[\mathrm{dB}]$} \\
\hline & 1253 & & 04995 \\
\hline
\end{tabular}

According to the Taguchi analyses the response can be predicted. A comparison of the predicted values and actual results were made. The error was calculated as the difference between actual and predicted values of $\mathrm{S} / \mathrm{N}$ ratio.

\section{References}

[1] H. Pihtılı, Europ. Polym. J. 45, 149 (2009).

[2] B.F. Yousif, N.S.M. El-Tayeb, Tribol. Int. 43, 2365 (2010). 
[3] T. Larsen, L.T. Andersen, B. Thorning, A. Horsewell, M. Vigild, Wear 262, 1013 (2007).

[4] B. Suresha, G. Chandramohan Siddaramaiah, P. Samapthkumaran, S. Seetharamu, Mater. Sci. Eng. A 443, 285 (2007).

[5] S. Basavarajappa, S. Ellangovan, Wear 296, 491 (2012).

[6] S. Biswas, A. Satapathy, Mater. Des. 31, 1752 (2010).

[7] K. Gupta Siddhartha, Mater. Des. 35, 467 (2012).

[8] A.Kr. Mishra, R. Sheokand, R.K. Srivastava, Int. J. Sci. Res. Publ. 2, (2012).

[9] S. Venkat Prasat, R. Subramanian, N. Radhika, B. Anandavel, L. Arun, N. Praveen, Europ. J. Sci. Res. 53, 280 (2011).
[10] T.R. Hemanth Kumar, R.P. Swamy, T.K. Chandrashekar, J. Miner. Mater. Character. Eng. 10, 1179 (2011).

[11] G. Taguchi, Taguchi on Robust Technology Development: Bringing Quality Engineering Upstream, ASME Press, New York 1993.

[12] ASTM G99-95 Standard Test Method for Wear Testing with a Pin-on-Disk Apparatus.

[13] C. Soutis, Mater. Sci. Eng. A 412, 171 (2005).

[14] K. Palanikumar, Int. J. Adv. Manufact. Technol. 36, 19 (2008). 